\title{
Florestan (from Conversations over Stolen Food)
}

\author{
Jon Cotner \& Andy Fitch
}

From antiquity to the present, social theory has often fused critical and creative discourse, esoteric and exhibitionistic tendencies. Socrates and Diogenes first announced many of their most radical propositions in the Athenian marketplace. Thoreau sowed his solitary beans while remaining (as scholar Stanley Cavell suggests) just barely within his neighbors' view. And now, as archivists of evanescent urban experience, as grazers of the public space, we have recorded forty-five-minute dialogues for thirty straight days around New York City.

Half these talks took place at a Union Square health-food store which, for legal reasons, we call "W.F." Other locations included MoMA, the Metropolitan Museum of Art, the Metropolitan Opera House, Central Park, Prospect Park, and a Tribeca parking garage. For this special issue on villains, we present the first dialogue.

7:43 p.m. Friday, December 30

Union Square W.F.

[First minute garbled]

A: ... scone and bagel, told her I'd already purchased them. I paid for a turkey burger (three dollars ninety-six cents). I held in my gloved hand a kiwi, and as I peeled off the glove I wrapped the kiwi in the glove. I put the gloves in 
my hat and put that in the cart - then I grabbed a bowl of spinach, baby spinach, organic of course. That cost a dollar five. So so I did spend more than hoped: 5.01 altogether.

J: But getting a considerable...

A: Yeah. A full meal.

J: And allowing us to have this conversation.

A: Correct, which at eight dollars might seem extravagant. It would mean the night had to end immediately. When I bought the turkey burger, or selected the turkey burger, the cashier, I mean deli guy, said he sensed I want to party tonight.

$\mathbf{J}$ : And this is your idea of a party right?

A: Oh yeah. Oh yeah. We've seen people we know. There's that man I have a crush on. There's the boy I saw. A former student stepped into the aisle. Her name's Fong.

J: Fawn, is that right?

A: F-o-n-g. Like fang.

J: Oh Fong.

A: Fang with an $\mathrm{O}$.

J: I've read an email she once sent you.

A: Extremely polite.

J: And as as I remember, you said a great student.

A: One of my best.

J: A hard worker and talented.

A: It frightened me in the bread aisle. Fong craved discipline and I pictured her disciplining me tonight. So have you adjusted to being back, back back in New York?

J: That's tough, let me tell you: it's an expensive city. I could never return if you hadn't arranged... 
A: Happy to do so. Can I interrupt one sec? Does this have saffron, or curry or something?

J: I don't know what's all...

A: $[$ Muffled $]$ out later.

J: in Royal Ginseng tea. Though I've stashed the box...

A: With aromatic...

$\mathbf{J}$ : right here. Here's the list of ingredients.

A: Maybe cinnamon bark?

J: Cinnamon bark you've tasted.

A: Honeybush. Licorice.

J: Black pepper.

A: Possible. But sorry, I shouldn't interrupt. New York seemed more...

J: It's an expensive city; I couldn't move back from Providence if you hadn't arranged this cat-sitting gig. Still the place needs work. I didn't get good sleep. The cat would jump from floor to windowsill, rattling a shade, and then leap down again rattling the shade, and I woke so often, and the apartment faces the BQE. Sharon claimed she lived in the heart of Clinton Hill but but her building stands on the edge of Fort Greene. That makes a huge...

A: Yeah.

J: difference. Traffic roars by nonstop. When trucks speed past it sounds as if they'll tear through the room. The studio costs $\$ 1210$ a month-which seems incomprehensible considering it's nowhere near subway stations, too close to highways and contains a cat active all hours of night. Though I guess her landlord...

A: Oh, will you have to maintain this the secrecy?

J: No I made a joke, implying the landlord should charge less considering a cat stays active all hours. Yet clearly the cat belongs to Sharon not...

A: Now this cat kept touching you? 
J: I'd wake to the cat clawing my toes, then try to kick it away thinking It won't come back; it got the message; survival of the species depends upon learning when it's not welcome. But the cat kept coming. However this morning, after several hours of running around and sensing my complete indifference, the the cat took not just a catnap but a substantial nap, and I felt some peace and could recuperate...

A: Or what about...

J: from the trip.

A: a fan in the apartment? Perhaps if you blew the fan...

J: I've searched all over for a fan.

A: Do you want one of mine?

J: That would be great if I could borrow a fan and drown out some traffic.

A: Drown out traffic-plus if you blow the fan near you (though not in your face) it might deter the cat from approaching the bed.

J: Cats don't like breezes.

A: Yeah they dislike the sound, and hate strong breezes, so one...

J: Don't get me wrong. I can't complain about Sharon's place. Of course it includes a cat and nowhere to grocery shop, which explains why I've bought groceries to take back with me: Liquid Aminos and fruit for morning. The packaged quinoa looked much too expensive. New York lacks bulk-bins because I guess that's not sanitary. See I've grown used to shopping in the Wild West, where I attended school, or New England where I'll often live, or St. Louis visiting my parents. There you find bulk-bins. Here they don't...

A: $[$ Muffled $]$ picture ten options. But won't you worry bringing produce to MoMA?

J: Because they search bags?

A: They'll sometimes ask Camera, wallet, also food. If you pack more than...

J: My phone will stay in the bag as usual, and I'll bring an orange and banana and deny they're there. I don't want any backpack to come between me and "Upside-Down Ada" by Katz. I've just read... 
A: Wait, is the Katz show on? We should include it in our time together, along with tremendous walks.

J: Absolutely.

A: Maybe strange excursions to a beach in winter.

J: I'd I brought my dad's car after all. We ought to fire it up and make use of it. That might deter my neighbors from breaking into it. They'll see it's cared for and not abandoned.

A: If we could get to a greenhouse...I especially love greenhouses in winter.

J: Yes I'm sure the right one awaits us, maybe Westchester...

A: We've nev...

$\mathbf{J}$ : on a private estate.

A: Though what's the plan for when time runs, your free apartment runs out in Brooklyn?

J: Well once recovered from this past week in Providence-I applied to SUNY Buffalo and said farewell, at least for now, to this sweet girl I'd started seeing, and said goodbye to some pleasant walks I've grown accustomed to-anyway all that exhausted me then I had a drive, not to mention packing the apartment (I should have said, rather, I had to pack my apartment, not to mention the drive). It drained me. Last night I'd needed good sleep I didn't get. But once my strength returns I'll look at rooms and prolong my stay here, probably around Columbia. That neighborhood offers everything I need: quiet hours reading in Labyrinth Books, rustic trails down Riverside Park, plenty of places to to buy fruit and quinoa.

A: I slept bad also.

$\mathbf{J}$ : What happened at Kristin's?

A: My flight landed around eleven, or I got back to Kristin's about eleven.

J: Did your flight get delayed?

A: Several hours.

J: For what? 
A: I don't know. Blizzards or something. Still I chose to risk-I'd napped already, but decided to drink valerian-root tea.

J: Ooh.

A: When I do this at the exact right moment it feels like sprinting downhill all night. Sleep turns tremendously pleasurable and...

J: From so much...

A: $[$ Cough $]$ pure gravity. That didn't work last...

$\mathbf{J}$ : What happened?

A: I'd wake at erratic intervals, or dream ab about lying in bed thinking.

J: Which doesn't amount to restful sleep.

A: I finished; I felt...

J: You had a restless dream.

A: puffy after I got up. Though this song about stealing entered dreams, which I took as a good omen.

J: Is that right?

A: "No longer wheeling, but but stealing."

J: No longer wheeling but now stealing — as though wheeling stood in contrast to stealing?

A: As though we've settled into life, to some extent a sedentary life, yet one that includes its own adventures.

J: Right, and wheeling suggests moving without much thought, whereas intense deliberation goes into choices we make: the fact that we'll sit side-byside on this bench in the upstairs W.F. café while a hundred people enjoy meals and conversation, and as janitors sweep crumbs from the floor.

A: Scanning this crowd I spot families and intellectual children. I'll see adults who live busy lives but still respond delicately to kids. It makes me feel part of the community as much as any place in New York does.

J: That's a major reason I enjoy eating here. Though though I may exist at 
the margins in this store, ripping off broccoli and shredded carrots and brown rice (which tastes unnecessarily salted), though I may not buy everything I'll eat, still I become part of the scene and it's pleasing. It beats eating alone at a desk most nights.

A: Did that happen this fall?

J: It happened in Providence. Often I ate alone in fact. I'd read during dinner, which felt fine. Those experiences build character.

A: Hmm I've lifted a Harper's, just to try out...

J: We know some of the staff so that should be ok.

A: I did wonder if he, if Harper's loses money on the theft. Would you...

J: No I don't think so. Perhaps the store loses a bit of money. Still...

A: Now I'd hoped we wouldn't mention this store's name.

J: Oh we can always edit that.

A: Right. But I'd like to say I embrace this this store as a socially beneficial one; I question my taking things from here. They have...have we discussed that companies contest the organic label? A consortium of food-industry lobbyists tries to reduce the "organic" criteria, so...

J: You're kidding.

A: factories can add synthetic elements to what still gets called organic food. And W.F. leads the charge against—one chain won't cooperate...

J: I didn't realize they had a sense of ethics. I'd thought they mostly worried about making profits. I had no idea.

A: Well thousands of co-ops could tell you this place doesn't care much about ethics. [Pause] I also read in the Sunday Magazine that food brands I'll identify with come from major corporations. Muir Glen for instance...

J: Yes.

A: A standard, right?

J: A staple. 
A: Great tomato sauce, soups taste good.

J: That's right.

A: Kraft, I think. No General Mills owns it.

J: Why...

A: Boca Burgers - again a constant of mine, always several in the freezer-I think Kraft owns that. They form front-companies. Boca Burger gets based in Madison Wisconsin to make it look like a nice, progressive, granola (we'll have to take that word out) food source, yet offers more of the same.

J: Well well if you think about it, we inhabit a corporate culture providing tons of choices. Should we place effort... should we try to escape this culture? Or should we settle down and make ourselves at home as life keeps drifting in this direction?

A: Impossible to decide. But we lose much while complaining. As I'd started to complain I noticed less. Just before I'd felt better and watched a girl with um humongous breasts approach that guy with curly hair, hand him a letter then run off giggling.

J: Here in the café? I stared at a different...

A: This man laughed with a person seated opposite, someone he didn't know, so that situation too derived from the letter.

J: Was the girl good-looking?

A: Very much so. The the man circled around twice after denying interest in the girl.

J: Well did he recoil because he's repressed?

A: I doubt we can...

$\mathbf{J}:$ Because he wants affection to take recognizable forms and exclude spontaneous development? Does he need all love to look the same?

A: I've responded similarly when confronted by women. Am I all that repressed? How could we gauge it? I'll experience joy watching people stretch here. I'd assume repressed people don't notice such things. Occasionally I get lost watching people get lost scooping fruit from cups held close to their 
mouths - as if eating noodles.

J: I picture outdoor restaurants in Beijing, not that I've traveled to Beijing: I've watched some Chinese films and can recall images of couples sharing steaming noodles. [Silence] So you consider this a fitting place to hold conversations, a pleasant forum, a suitable environment?

A: I think of Kierkegaard in the town square and I'm...

J: Not his study, right?

A: thrilled to work on a project again. Ascending the Hudson this afternoon I felt (for for the first time since drafting Sixty Morning Walks...

J: A splendid project.

A: we'll see, still to be finished) the flush when obstacles get thrown in your way, maybe of your own doing, maybe that's better. Since...we'll live in New York yet stray to a backward country, leaving all but the most elemental problems.

J: Such as?

A: Such as how position our bodies best to survey the scene; how explain to others, well the irrational element, in terms of potentially getting caught, a disproportionate...

J: Yeah and I'm thrilled to be here. I'd I just got distracted by...

A: What?

$\mathbf{J}$ : the girl with rosy cheeks.

A: That woman wearing violet?

J: Actual rosy cheeks, as if I've looked at some Danish portrait from the $18^{\text {th }}$ century. Few people have her robustness these days. And her skirt, rather her sweater reveals her abdomen, which she massages while talking to a friend: aware of patrons watching fr...

A: Um I used to massage myself during soccer games, specifically throw-ins, without — wow she's kissing that girl.

J: What part of... 
A: She just...

J: yourself would you massage?

A: frenched that girl across the table.

J: Maybe to show she doesn't...

A: Go that way?

J: swing my way, and I should take my eyes off her. But I have removed my eyes from her.

A: The girl she kissed has what looks like an Ash Wednesday ash on her forehead.

J: Right, a jewel signifying spirituality.

A: Do you think the rosy girl's cheeks glow because of pink beneath her purple top, just barely sticking out? Does that make us more attentive to to colors farther up?

J: Perhaps her cheeks catch pinkness from the fabric, though beauty often possesses flushed cheeks.

A: Don't...

J: On a a normal day I'd invite them over. Already our project has instilled strict discipline. Yet constraint puts me in touch with things.

A: Yes as soon as we decide to not go on imagination we'll look around and discover enough to be pleased by.

$\mathbf{J}$ : We may find far too much in fact. It is it's remarkable, and makes me happy New York is on the map, and despite corporate pressure a tangible spirit...

A: I only realized how dull I'd felt the past ten days when I stepped out this morning.

J: You went back ten days? Wow. I liked what you said last week: that since you'd gone home for Thanksgiving and Christmas I was exempt from going home. My my sister's moved to Nashville. She and her husband celebrated Christmas there. I worked on the Buffalo application, spending time with, well I almost said my girlfriend, but I mean this girl I've started seeing (who lives in a small Massachusetts town). Still Christmas Day I got swamped 
with thoughts of how my parents keep aging, how I don't have endless Christmases to see them.

A: Whereas I got swamped by the incessant reinforcement of personality which...

J: Without...sorry go on.

A: [Muffled] that I did when four. We discussed me as a four-year-old.

J: Did anyone ask about your graduate studies?

A: Nobody mentioned life in New York. But perhaps this gets caused by me asking questions. I feel I tend to pounce on people. I'll ask a question. If they respond somewhat tentatively I'll ask five more. And though I prefer to stay the active person I've found myself bored with what people have to say. I don't mean around family; I'm sketching a social situ...

J: So for now you'd feel inclined: say you attend a party with unknown people...

A: I'm thrilled to meet unknown...

$\mathbf{J}$ : But instead of going over and asking questions about their lives, you'll let them remain silent beings?

A: No I love to ask about people's lives. I'd just hear lots, a lot of repetition because I'll demand responses I don't-yet I got screwed up not having my daily rhythm this week, so I could relate to speaking without caring what you say. I've had a...

J: Why why don't you discuss a bit how your ordinary rhythm contributes to life. What's that set of activities you'd undertake each day when...

A: Oh. Oh my god I saw...I'm listening.

J: You see somebody you know?

A: A woman that lived next door to me.

J: On $110^{\text {th }}$ ?

A: My first year in New York, on East $16^{\text {th }}$.

$\mathbf{J}$ : Oh the that old woman? 
A: Yeah in...

$\mathbf{J}:$ Oh in the long blue coat. Yes and she has sweatpants rolled...

A: She'd...

J: almost to her knees.

A: offer me Pepsi since I'd carry her laundry cart. I'd put...

J: Still you had to decline the Pepsis I'm sure.

A: I didn’t want a Pepsi.

J: But she kept offering you the Pepsis?

A: Her sister developed dementia and accused my...

J: Does she live with a sister?

A: She did. The sister fell long...once stairs stood (to some extent) smeared with blood.

J: She's she got up and walked away from it?

A: $[$ Cough $]$ head injury. No, I didn't see her after that.

J: Well New York may have had another tombstone af...

A: What were we discussing?

J: We'd mentioned your daily rhythm and how, when you do what you want, living according to your own ambition or inclinations, you care very much what you hear-what's being said and what people say back.

A: And you want to know where these rhythms...

J: Yeah. Yeah. To give others a sense, because it's a thoughtful set of activities. It influenced my life tremendously. I mean people laugh: Amanda, for example, laughed when I said my breakfast lasts three hours. Then I went into a description of how I'd learned the three-hour breakfast from my best friend Andy.

A: Whose breakfast now takes seventy-five minutes. 
J: Incredible.

A: Though I'll include meditation, so you could say two hours and...

J: Every morning?

A: Yes. I wake from eight hours of sleep. I'll want...

J: Do you ever set an alarm?

A: Always.

J: If you don't set an alarm would you sleep close to nine?

A: I'd stress and wake earlier.

J: Because you'll think you've overslept.

A: Sleeping nine hours makes me feel off.

J: So you get hard on yourself?

A: It seems quite gentle.

J: Waking in a panic, thinking you've overslept by an hour?

A: Oh. My means of gentleness is to to set the alarm and avoid that situation.

J: I see.

A: Then I stretch while cooking hard-boiled eggs. I'd...

J: You'll cook hard-boiled eggs each...

A: Every other morning. I was giving the condensed version.

J: No give us the condensed version.

A: Ok. Ok. I've timed stretching to last fifteen minutes-for how long it takes to boil my eggs. After, and this lets me poo. Someplace in there I can poo.

J: Before you've eaten anything?

A: Yeah, if I stretch. After that I'll meditate... 
J: Your eggs cool as you meditate?

A: an hour and eat breakfast in...for a total of two hours fifteen.

J: You eat nothing before meditating? Yeah I hear John Stuart Mill, before eating breakfast, would work through Greek and and Latin exercises, and this is before he'd turned ten years old.

A: When you lived with me, I don't know if you'll remember this time, but when you and Stephen rented my room with me for...

$\mathbf{J}$ : Oh yes, that summer we split your room in Williamsburg.

A: Right it...

J: [Cough] a great summer. You'd leave James Schuyler or Joe Brainard on your desk, and I'd sit in boxers reading those books. Your roommates would kindly acknowledge my presence. They looked baffled when our stay exceeded two weeks yet didn't confront us, which I found noble.

A: I have never felt so insomniatic. I'd try to concentrate before breakfast (before the full day started) think - wait here comes...

J: Morning freshness...

A: here comes my neighbor.

J: Yes maybe we want to...

A: No, we don't.

J: say hi to her? No? Ok. But I waved...

A: You saw that snarl.

J: She snarled and looked down yeah; she...

A: Those are aliens on her shopping bags?

$\mathbf{J}$ : has aliens printed on her shopping bags. Her coat hangs wide open. Her scarf dangles messily almost to the floor. Do you think she grew up on East $16^{\text {th }}$ ?

A: I've read a passage in I Remember, sorry More I Remember, you know, the version before the edits, the final edits, in which Joe Brainard roomed 
with Ted Berrigan in an an apartment in the East Village, and the woman above used to come squeeze them. Did you...

J: Squeeze them? No I never read this passage.

A: She and her brother, who had mental problems as well could barge...she'd force herself into the apartment.

J: Really?

A: Brainard says she was huge.

J: He was very thin.

A: But he ends the entry saying most cities would lock her up, which seems true of my neighbor also...

$\mathbf{J}$ : Yeah such a...

A: and that's why we're here.

J: And similarly: in other cities someone would tell us to get the hell out of this café with our recording instrument.

A: You think?

J: We'd look conspicuous. Yet for now we've we blend...

A: Right I've got a final question for you. If we eat things before we exit can no one call...catch us? There's habeas corpus but there's something else. Body of evidence? Doesn't physical evidence need to exist of the event? So long as we consume all evidence perhaps nothing can be done to us.

J: Yeah, I guess we've created a body of evidence, but only we ourselves will listen to this tape, and, what's more, I've become friends with the security guards. They know me by first name, as I know them by first name. Today I spoke to...

A: Don't. You don't want to get them in trouble.

J: Tonight we shared reintroductions. Tonight's my first time in the this store for several months and I shook a lot of hands. It felt warm. It's nice to be welcomed back.

A: Now could you explain what happened in Providence? 
J: You mean...

A: Inside its W.F.?

J: Well I have to admit: the desire to keep my living expenses low became reckless. I would carry into the store a bag, a plastic bag from W.F., and I'd place it in the cart and, as I'd shop, I'd place things in the bag, and I'd place of course many many groceries outside the bag, but there were certain items, certain expensive items, that I'd place in the bag - such as sirloin steaks and blueberries (for a while they cost 5.99 a carton). I'd drink an expensive ginseng tea. There was this hot sauce I'd steal, pure extravagance of course and I knew I had turned sloppy, yet I knew...

A: You know the thief's main virtue is modesty? A modest thief never...

J: That's right.

A: I'm guessing. I'm guessing.

J: You're right. And I was modest tonight in stealing my my steamed broccoli and shredded carrots and brown rice, which tastes unnecessarily salted, and that explains why I keep drinking water. You'd think a place committed to health wouldn't salt foods so excessively.

\section{A: So what happened? So?}

J: So just as I left the store an undercover guard blocked my passage. He said Excuse me; I'd like to speak with you inside. And I looked at him and said I don't know what you're talking about. And he said Oh, you don't know what I'm talking about? I said No I don't. And he said You left the store with unpaid merchandise. And I said What? And he pointed to the bag containing my wrapped sirloin, which cost twenty dollars, and said I've worked in this business six years - get inside. The manager stood waiting for me, totally baffled, since we were likewise on a first-name basis, and after previous episodes of stealing (in an effort to keep expenses down) I would treat him with lots of affection: shaking his hands, wishing him a good night, telling him I'd see him real soon. He led me into an office, where he did not press charges. He firmly believed I was confused. That became the story; I'd got confused. I said I'd started talking with the cashier about her necklace. She wore this charm made of imitation gold which spelled her name in cursive and...

A: Hmm, I saw one on this woman sweeping. If you can read the name I'm curious. It looked very long, like Florestan. 
J: Florestan, is that right?

A: But the necklace hangs backwards, so you'll have to read backwards. But sorry go ahead.

J: Yes. I said I got confused: I'd asked about a girl's necklace. I said I'll pack my groceries apart from my roommate's since she's vegetarian. I said I myself used to be a vegetarian, and know what it's like. I said I'd just started eating meat again and just got confused. And the manager kept nodding with a blank expression, neither agreeing nor disagreeing while the undercover processed the paperwork. I said Can't we talk about this? The guard said No. He snapped my photo and said If you ever step into another W.F. you could be arrested on the spot. I started thinking of this project, not wanting to jeopardize it, yet of course didn't say anything. It's not like I could have said Oh but sir, come two months from now I've planned conversations over stolen food with my friend Andy. Please don't stand between me and this project.

A: Today's Times contained pieces on shoplifting. One gave the undercover...

[Tape runs out] 

Iowa Journal of Cultural Studies 14 (Spring 2013)

Copyright (C) 2013 by The University of Iowa 